\title{
Experimental and numerical analysis of an industrial RC tower
}

\author{
T. Tatara ${ }^{1} \cdot$ F. Pachla ${ }^{1} \cdot$ P. Kuboń ${ }^{1}$
}

Received: 18 May 2016/Accepted: 15 November 2016/Published online: 26 November 2016

(C) The Author(s) 2016. This article is published with open access at Springerlink.com

\begin{abstract}
This study presents the results of analyses performed using a dynamic 3D model of a RC skip tower located at a coal mine in Poland. Kinematic excitation was based on acceleration records of a mining tremor (underground mining activity) and an earthquake. Although Poland is not a particularly active seismic region, there are regional seismic phenomena associated with mineral exploitation. These vibrations, generally connected with human activity, are so-called paraseismic events. Whilst mining-related surface vibrations show some similarities with natural earthquakes, there are also some differences. Dynamic calculations were performed in the time domain. Analysis of the results refers to the distribution of stresses and displacements which were compared to the limit values. An additional goal of the study was to examine the possibility of loss of structural stability and the risk of collapse. The reason for making the analysis was the fact that kinematic excitations of high structures had not been taken into account in the design procedure. Using actual recorded surface vibrations caused by rock burst and earthquake as kinematics loads allowed a comparison of the dynamic responses of the structure with two different seismic events.
\end{abstract}

Keywords Earthquakes - Mining tremors - Surface vibrations - Industrial structures

\author{
P. Kuboń \\ pkubon@pk.edu.pl \\ T. Tatara \\ ttatara@pk.edu.pl \\ F. Pachla \\ fpachla@pk.edu.pl \\ 1 Cracow University of Technology, Kraków, Poland
}




\section{Introduction}

Among the many loads that can affect buildings, kinematic loads are particularly significant. Such loads can result from earthquakes or paraseismic events-from the latter, we can distinguish vibrations caused by both underground and surface mining. These vibrations could cause significant damage to surface structures (Ciesielski 1973; Gad et al. 2005; Singh and Roy 2010; Tatara 2012; Manfredi et al. 2014). In Poland, there are regions of large paraseismic activity caused by underground mining exploitation. Among particularly active regions are: the Upper Silesian Coal Basin (USCB) (Tatara 2012); the LegnickoGłogowski Copper Region (LGCR) (Pytel 2003; Tatara and Pachla 2010a, b ; Zembaty 2004, 2011; Tatara 2012; Kuźniar and Tatara 2015; Maciag et al. 2016) and the Bełchatowski Brown Coal Region (BBCR) (Tatara and Pachla 2010a, b; Tatara 2012). In many cases, the structures situated in these areas were neither designed for nor verified for additional seis-mic loads resulting from buildings vibrations. This also concerns structures involved in mining operations - shaft and skip towers, which transport output from a mine, are surely among such components. Wind load was the basic load considered in the design process of such structures due to their heights. Dynamic loads originating from mining operation were not included in the design process. The vulnerability of such structures to dynamic excitations couldn't be neglected. According to EN 1998-1 Eurocode 8 1998, assuring reserve bearing capacity due to nonlinearity of materials is not allowed during the design of special structures (behaviour factor $\mathrm{q}$ is 1.0). In the case of dynamic analysis using RSA, depending on the analysed structure, EN 1998-1 Eurocode 81998 allows linear work by modifying the elastic response spectrum using the $\mathrm{q}$ factor. The values of the $\mathrm{q}$ factor for RC structures with load bearing walls are in the range 1.5-4.8 depending on the structure ductility (EN 1998-1 Eurocode 8 1998).

Thus, it seems justifiable to make dynamic calculations in order to check the dynamic resistance of the tower due to additional inertia forces caused by mining shocks, and to compare it with resistance to shocks resulting from a typical earthquake. The study dealt with the dynamic analysis of an RC skip tower located near a pit-coal. The tower hoisting is an object of strategic importance for the mine field. Its faultless functioning ensures the continuity of work and production. The tower is representative of this type of high reinforced-concrete structure in industrialised areas. All calculations were performed using the 3D Finite Element Method (FEM) model. The dynamic characteristics of the model were verified by means of dynamic tests performed on the real structure.

\section{Analysed structure}

The discussed tower is made of reinforced concrete and is supported by four pylons. Its dimensions are $6.7 \mathrm{~m} \times 6.5 \mathrm{~m}$ and the thickness of walls is $30 \mathrm{~cm}$. The columns are founded by means of a RC grid. The foundation of the tower consists of a RC plate with a thickness of approximately $1.5 \mathrm{~m}$. The plan dimension of the rectangular plate is $25 \mathrm{~m} \times 34 \mathrm{~m}$ with truncated corners $(2.5 \mathrm{~m} \times 2.5 \mathrm{~m})$ and a $10 \mathrm{~m}$ diameter opening for a skip pipe. The inset-skip pipe was treated as independent, therefore, the mechanical characteristics of its connection were not considered during FEM calculations. The foundation is located $7.5 \mathrm{~m}$ below the ground surface. The foundation plate in the basement part is stiffened by a RC grid with 6-m-high walls. The beams hidden in the thickness of the plate constitute the ribs of the grid. The ribs run under the walls of the tower. The 
total height of the tower from the foundation level is more than 100 meters. Figure 1a shows a photograph of the analysed structure.

The basic data characterising the construction of the tower and the technical devices are as follows (Tatara and Pachla 2011):

Dimension of transverse section-27.30 m $\times 18.30 \mathrm{~m}$,

Total height of the tower from foundation level-101.77 m,

Height above the ground surface- $-95.77 \mathrm{~m}$,

(a)
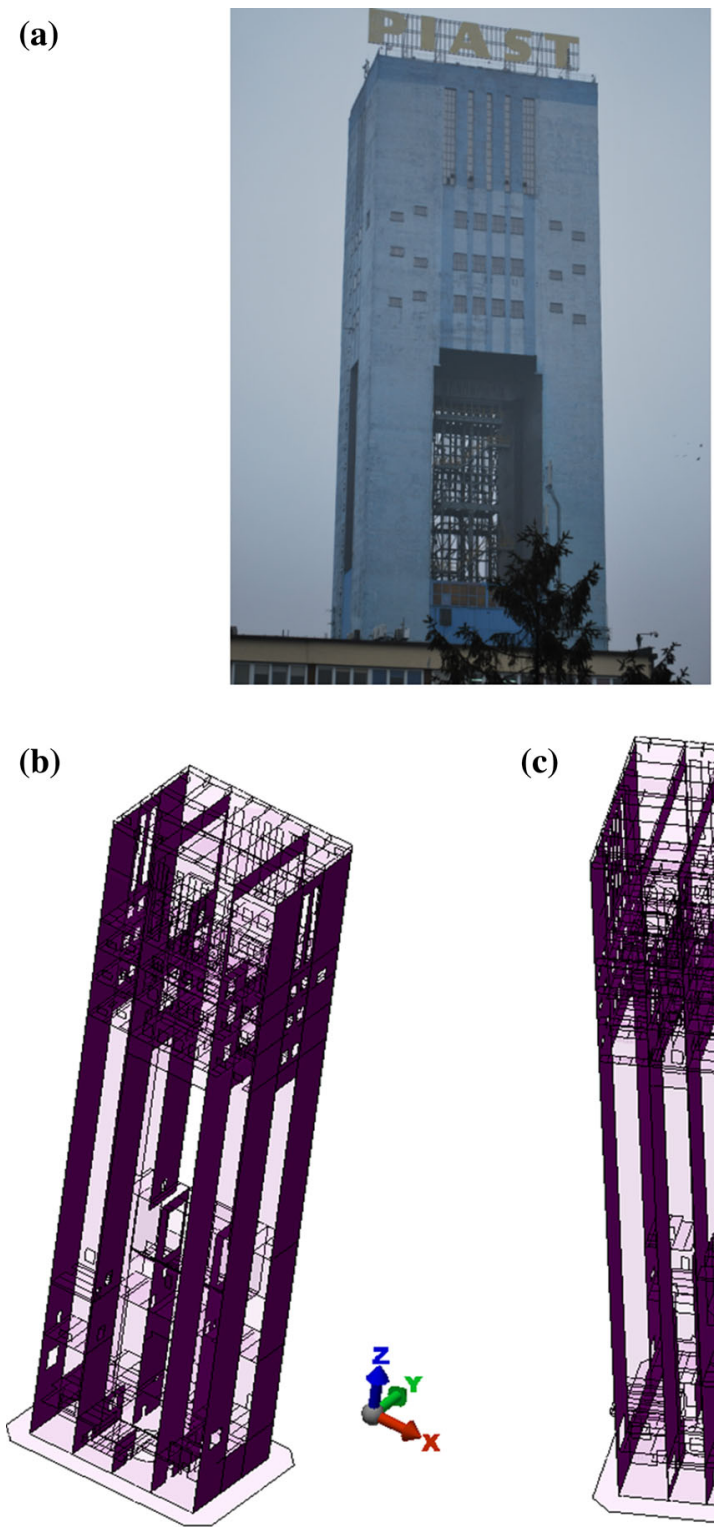

(c)

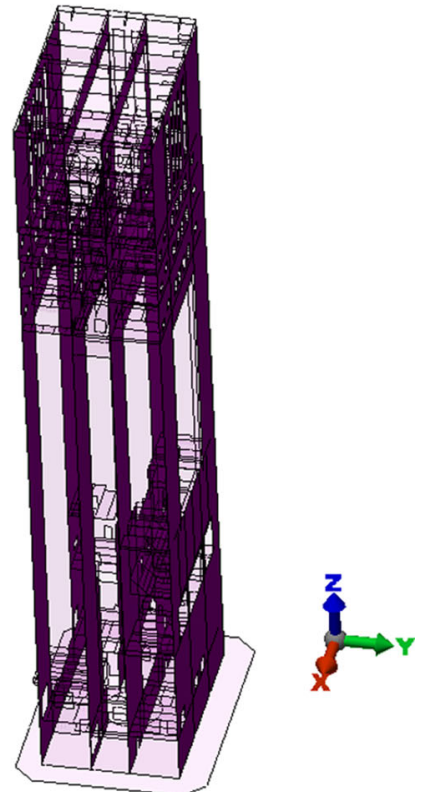

Fig. 1 The analysed RC skip tower 
Level of axis of sheave wheels- $64.32 \mathrm{~m}$,

Diameter of sheave wheels- $5 \mathrm{~m}$,

Level of axis of fly-wheels-80.01 m,

Diameter of fly-wheels- $5.5 \mathrm{~m}$,

Telescopic connection of the columns of trunk at the level of $-53 \mathrm{~m}$.

With regard to the geometry of the structure, practically full symmetry of the structure appears in two directions. Walls of suitable stiffness in the transverse ' $y$ ' and longitudinal ' $x$ ' directions are shown in Fig. 1b, c. For walls in the transverse direction (see Fig. 1a), the symmetry can be seen in the upper part of the structure. This symmetry is disturbed in the section below ground level-here, the grid is formed with transverse and longitudinal walls which have significant stiffness in comparison to the upper section. In the longitudinal ' $x$ ' direction (Fig. 1c) a lack of symmetry is observed - this is mainly caused by the structure of the rear wall, where temporary coal bunkers are located.

The tower is constructed using a sliding method and it has 10 levels incorporating RC constructions in the form of ceilings and prefabricated plates supported by steel beams. The main bearing system of the tower consists of RC columns (pylons). These pylons are extended to full wall-contour structure with a thickness of $30 \mathrm{~cm}$ using a sliding method, starting at a height of $63.60 \mathrm{~m}$ up to the top of the tower. The bearing walls of the tower constitute the support simultaneously for ceilings as well as machines and technological devices. All reinforced walls above $63.60 \mathrm{~m}$ are built as beam-wall elements in a similar manner to the walls of reservoirs. The walls of reservoirs are built as reinforced beams in two directions and realised using the sliding method. The walls under the grillage of the hoist machine were thickened to up to $50 \mathrm{~cm}$ to transfer the main stresses resulting from emergency loads. The ceilings of the tower were designed as RC prefabricated slabs supported by steel or RC monolithic beams. The roof is built of RC precast slabs $(12 \mathrm{~cm}$ thick) and of RC prefabricated elements or the monolithic slabs leaning on main beamsthese are fragments of suitably rearmed RC walls - and also on steel beams.

The roof surface is covered with roofing paper. The gantry beams are constructed from steel. In the machine hall there are two hoist machines and the gantry with a lifting capacity of $32.0 \mathrm{Mg}$. The cage-guide of hoist devices is a steel grid construction. The tower is located on flexible ground B type (EN 1998-1 Eurocode 8 1998).

\section{Numerical model}

The principal stage of the dynamic study was focused on creating a numerical model of the discussed skip tower. The model of the structure was built using the finite element code ALGOR and data from available project documentation (Tatara and Pachla 2011, 2012). However, although a certain repeatability of geometry is visible, there is no full symmetry of structure. Therefore, the 3D model of the tower was analysed. All essential elements influencing the stiffness of the model were considered. The steel trunk which serves for transportation of output from the skip was not considered in the model. Taking into account the formulation of the dynamic problem concerning the 3D structure, the stiffness and the mass of the tower were thoroughly imitated in the spatial FEM model. The global coordinate system shown in Fig. 2 allows for univocally describing geometry and loads as well as interpreting the results of calculations. A detailed plot of the model is shown in Fig. 3. 
Fig. 2 Geometric model of the skip tower with applied global arrangement of coordinates

(Tatara and Pachla 2011, 2012)
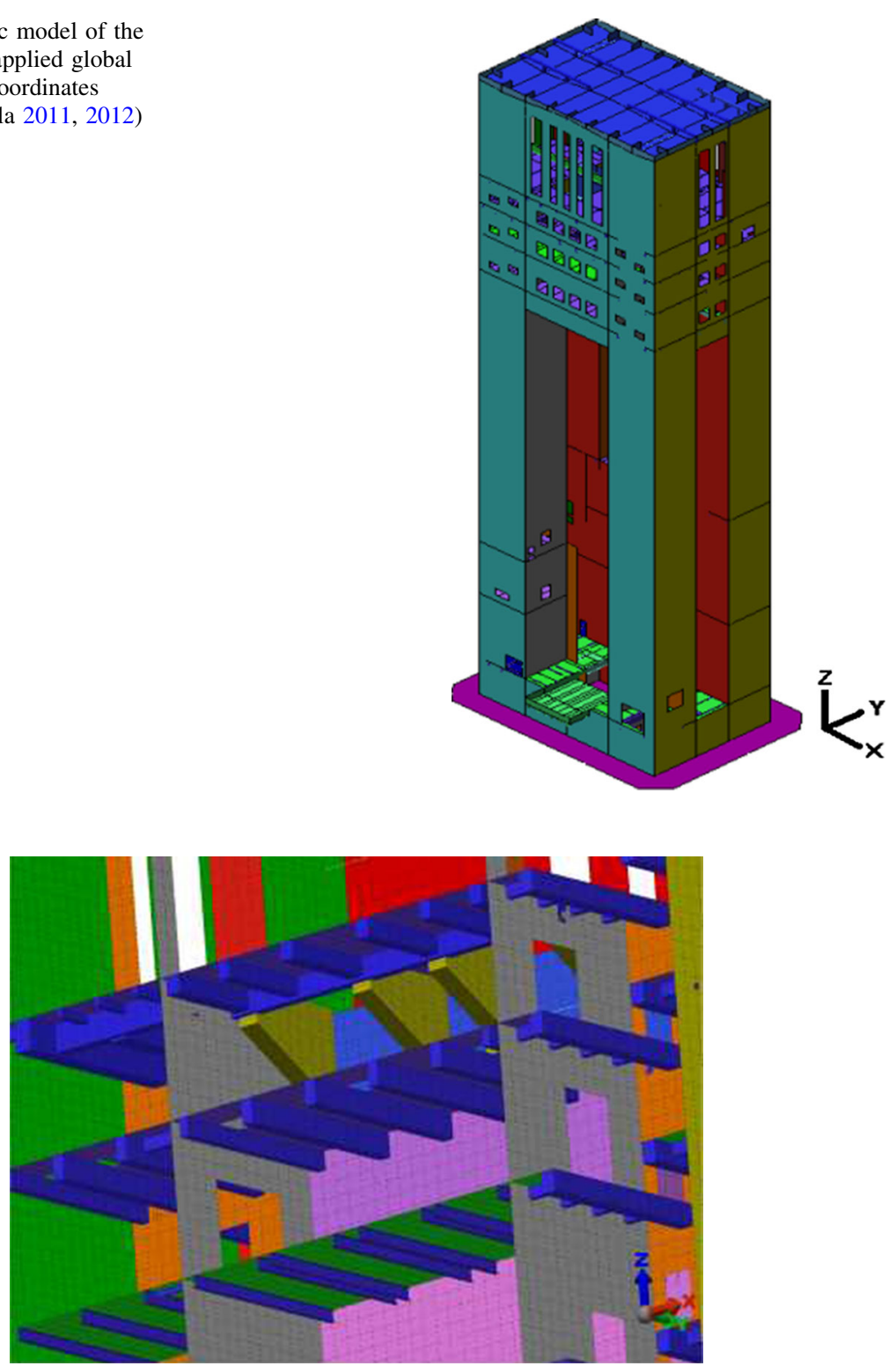

Fig. 3 Details of the model with 3D beam visualisation

Discretisation of the model resulted in 82,817 finite elements. Displacement FEM version was used for the analysis. This means that all quantities were calculated using an approximation of the displacement field inside each element on the basis of the displacement values in nodes. The bearing walls, the ceilings, the foundation plate and the beam-wall elements were modelled using shell elements with five degrees of freedom in every node of the element. The beams and columns were modelled by finite elements of the beam elements with six degrees of freedom in every node of the element. Additionally, for 
a more precise imitation of the ceiling stiffness, centres of gravity of beam elements were modelled including their eccentrics. The values of coefficients characterising the physical proprieties of materials were assumed according to the data from the archival project records, codes which were valid during the design as well as literature. Linear-elastic mathematical models for all constructional materials were adopted. These values are listed in Table 1.

The model corresponds to the original state of the tower. It was assumed that the structure is built correctly and that there was no damage present that would decrease stiffness. The model was adopted as linear-elastic. Such an assumption at the design procedure leads to significant values of inertia forces for mining shocks (Zembaty et al. 2015). The tower was subjected to the influence of mining tremors of varying intensity (including strong mining tremors with a return period of 2-3 years-Zembaty et al. 2015) during many years of operation.

Different properties of materials for the bearing elements in the dynamic model of the tower were considered. The combination of load representation describes dependence (1) according to code (PN-85/B-02170 1985):

$$
Q_{k}=Q_{k}^{\prime}+0.6 \cdot Q_{k}^{\prime \prime}
$$

where: $Q_{k}^{\prime}$-dead load; $Q_{k}^{\prime \prime}$-technological load, including live loads and loads due to normal work of the lifting devices.

The influence of soil properties was replicated through the application of springs at the bottom of the foundation of the model. Soil properties were taken from data obtained on the basis of geological surveys at the location of the analysed structure. The springs were applied in both horizontal and vertical directions at the bottom level of the foundation. The values characterising their properties correspond to the code values (PN-80/B-03040 1980).

\section{Dynamic characteristics of the model and its verification}

\subsection{Natural frequencies of the model}

The analysis of natural frequencies was carried out on a model of the tower. The natural frequencies and the corresponding mode shapes were determined using the FEM model of the tower. The model was supported by a system of springs the characteristics of which were calculated using the elastic uniform vertical deflection $\left(\boldsymbol{C}_{z}\right)$ equal to $60(\mathrm{MPa} / \mathrm{m})$, and horizontal deflection equal to $42(\mathrm{MPa} / \mathrm{m})$ - this corresponds to ground B (EN 1998-1

Table 1 Characteristics of assumed materials

\begin{tabular}{llll}
\hline Material & Density $\left(\mathrm{kg} / \mathrm{m}^{3}\right)$ & Young's modulus $(\mathrm{GPa})$ & Poisson's ratio $(-)$ \\
\hline Concrete '170' & 2500 & 26 & 0.167 \\
Concrete '200' & 2500 & 29 & 0.167 \\
Concrete '250' & 2500 & 32 & 0.167 \\
Steel St3S & 7850 & 205 & 0.3 \\
\hline
\end{tabular}


Eurocode 8 1998). This value refers to the actual properties of the ground under the foundation raft. The range of natural frequencies is relatively dense. Values of fifteen calculated natural frequencies and selected mode shapes are shown in Table 2 and Fig. 4, respectively.

Values of calculated frequencies equal to $0.5,0.72,1.53,3.06$ and $4.23 \mathrm{~Hz}$ correspond to vibrations of the model as a whole structure. The analysed model has a lot of natural frequencies and mode shapes corresponding to only local vibrations of elements. In this case, the values of effective modal masses are equal to zero in each row of Table 2. Mode shapes corresponding to the first natural horizontal frequencies in ' $y$ ' and ' $x$ ' directions, as well as the first torsional frequency of the analysed model, are shown in Fig. 4.

\subsection{Sensitivity analysis of the model due to ground properties}

The study also examines the sensitivity of the model according to adopted stiffness parameters of the ground under the foundation slab. The issue of natural vibrations is resolved for different ground conditions. The ground parameters correspond to different values of the coefficient of elastic uniform vertical deflection $\left(C_{z}\right)$. The ground parameters are assumed according to code PN-80/B-03040 1980. Table 3 shows the calculated values of the first three natural frequencies of the model for different values of coefficient $\left(C_{z}\right)$.

The character of the mode shapes corresponding to individual natural frequencies did not change. The values of natural frequencies of the model increase with increasing stiffness of the soil. The differences between the values of natural frequencies for the model with infinitely stiff ground and with the most flexible ground is nearly $44 \%$ for the first frequency $f_{1}$ and almost $50 \%$ for the second frequency $f_{2}$-see Table 3 . These two frequencies are related to the lateral vibrations of the tower in two orthogonal directions.

Table 2 First fifteen natural frequencies of the FEM model with values of effective modal mass

\begin{tabular}{|c|c|c|c|c|c|c|}
\hline \multirow[t]{3}{*}{ Frequency (Hz) } & \multicolumn{6}{|c|}{ Effective modal mass $(\%)$} \\
\hline & \multicolumn{3}{|c|}{ Translation relative to } & \multicolumn{3}{|c|}{ Rotation relative to } \\
\hline & $X$ & $\mathrm{Y}$ & $\mathrm{Z}$ & $X$ & Y & Z \\
\hline 0.50 & 0.00 & 60.09 & 0.00 & 96.40 & 0.01 & 27.55 \\
\hline 0.72 & 59.53 & 0.00 & 0.00 & 0.01 & 92.35 & 10.66 \\
\hline 1.53 & 0.30 & 0.00 & 0.00 & 0.00 & 0.68 & 21.25 \\
\hline 1.63 & 0.00 & 0.00 & 0.00 & 0.00 & 0.00 & 0.00 \\
\hline 1.63 & 0.00 & 0.00 & 0.00 & 0.00 & 0.00 & 0.00 \\
\hline 3.06 & 0.00 & 8.08 & 0.00 & 0.03 & 0.00 & 3.62 \\
\hline 3.33 & 0.00 & 0.00 & 0.00 & 0.00 & 0.00 & 0.00 \\
\hline 3.33 & 0.00 & 0.00 & 0.00 & 0.00 & 0.00 & 0.00 \\
\hline 4.00 & 0.00 & 0.00 & 0.00 & 0.00 & 0.00 & 0.00 \\
\hline 4.00 & 0.00 & 0.00 & 0.00 & 0.00 & 0.00 & 0.00 \\
\hline 4.23 & 7.52 & 0.00 & 0.00 & 0.00 & 0.13 & 2.23 \\
\hline 4.30 & 0.00 & 0.00 & 0.00 & 0.00 & 0.00 & 0.00 \\
\hline 4.30 & 0.00 & 0.00 & 0.00 & 0.00 & 0.00 & 0.00 \\
\hline 4.50 & 0.00 & 0.01 & 1.66 & 0.05 & 0.9 & 0.00 \\
\hline 4.55 & 0.01 & 0.6 & 0.16 & 0.00 & 0.01 & 0.28 \\
\hline
\end{tabular}




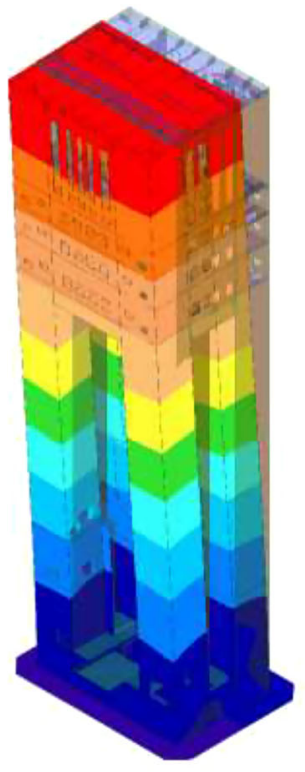

$\mathrm{f}_{1}=0.50 \mathrm{~Hz}$

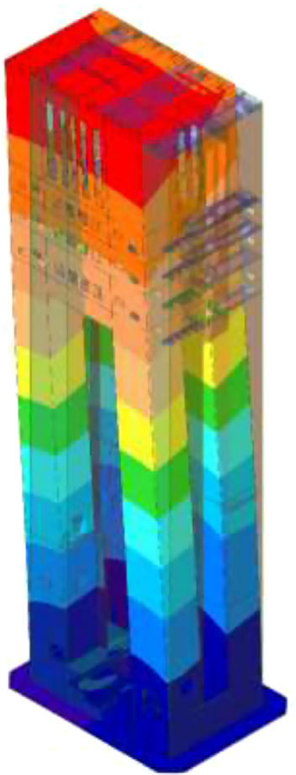

$\mathrm{f}_{2}=0.72 \mathrm{~Hz}$
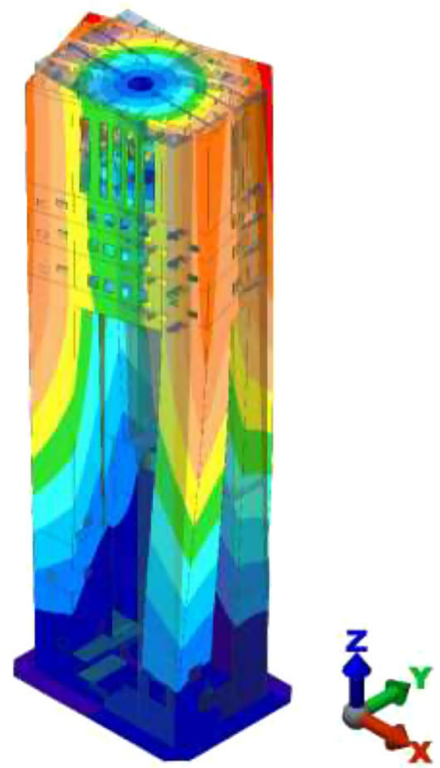

$\mathrm{f}_{3}=1.53 \mathrm{~Hz}$

Fig. 4 First three mode shapes corresponding to the natural frequencies of the model

Table 3 First three natural frequencies of the tower model for different types of soil

\begin{tabular}{llllllllll}
\hline Soil type 0 & I & II & II & III & III & IV & IV & IV & Fixed \\
$C_{z}(\mathrm{MPa} / \mathrm{m})$ & 20 & 35 & 40 & 45 & 50 & 55 & 60 & 70 & $\infty$ \\
\hline$f_{1}(\mathrm{~Hz})$ & 0.41 & 0.46 & 0.47 & 0.48 & 0.49 & 0.49 & 0.50 & 0.51 & 0.59 \\
$f_{2}(\mathrm{~Hz})$ & 0.58 & 0.65 & 0.67 & 0.68 & 0.69 & 0.70 & 0.72 & 0.73 & 0.86 \\
$f_{\mathbf{3}}(\mathrm{Hz})$ & 1.48 & 1.51 & 1.51 & 1.52 & 1.52 & 1.52 & 1.53 & 1.53 & 1.57 \\
\hline
\end{tabular}

The influence of ground stiffness for the value of torsional natural frequency, which corresponds to the frequency $f_{3}$, is not so significant and does not exceed $6 \%$.

\subsection{Verification of the model}

The dynamic measurements of the RC tower were made in one to enable the continuation of mining work. Sixteen measurement cycles were conducted in which the sources of vibration excitation were: the work of the lifting equipment (8 measurements); wind gusts (2 measurements); synchronized movement of men at the top operating level of the tower (6 measurements) (Tatara et al. 2013). Preliminary numerical analysis showed that the natural frequencies of the analysed tower are low. As a result, the appropriate instrumentation system and control equipment was chosen-this consisted of accelerometers, strain gauges, a four-channel amplifier, a 16-channel recorder, an oscilloscope, and a PC with specialised software to analyse the data records. Vibration tests were conducted by a 
team from the accredited Laboratory of Testing Distortion and Structural Vibrations Research located in the Institute of Structural Mechanics of Cracow University of Technology, including the paper's authors. The instrumental system consisted of PCB 393B12 accelerometers, a digital analyser LMS Mobile Scadas equipped with an analogue low-pass Butterworth filter 0-100 Hz. The above-mentioned apparatus was designed to measure the low frequency vibrations that occurred in the examined cases. The linearity deviation PCB sensor signal does not exceed $2.3 \%$. The relative standard uncertainty of the maximum acceleration signal resulting from installation errors, instrumental system and analysis does not exceed $\pm 11.61 \%$.

Measuring devices were installed at two levels of the structure. For measuring deformations of the tower, eight electro-dynamic strain gauges were fixed on pillars at the base of the skip tower about $1.7 \mathrm{~m}$ above the ground surface for measuring deformations of the tower (Fig. 5). At the level of the driving wheels ( $80.01 \mathrm{~m}$ above the ground surface) piezoelectric accelerometers were installed to measure horizontal components of vibrations in two mutually perpendicular directions ' $x$ ' and ' $y$ '. Figures 6 and 7 show the selected measurement points with the applied accelerometers and how they were attached.

Table 4 includes the maximum values of the vibration acceleration recorded at the level of the driving wheels. The comparison of the data from Table 4 shows that both in the case of wind and synchronized swaying men excitation, the maximum vibration acceleration values are higher in the ' $y$ ' than in the ' $x$ ' direction. This is the result of the difference in the stiffness of the tower in ' $x$ ' and ' $y$ ' directions. The structural stiffness of the tower in the ' $y$ ' direction is lower than in ' $x$ ' direction. The level of vibrations caused by machines was the highest in the ' $x$ ' direction due to the applied extraordinary load generated by the moving bearing ropes.

Two stages of analysis of the recorded signals were conducted. The first stage considered filtration of the signals using a digital low-pass filter with cut-off frequencies equal to 5 and $10 \mathrm{~Hz}$. The analysis was then carried out in the frequency domain using FFT, the PSD and the cross-correlation function CSD between the set of signals (Signal Processing

Fig. 5 Measuring post (strain gauge) located at the base of the tower

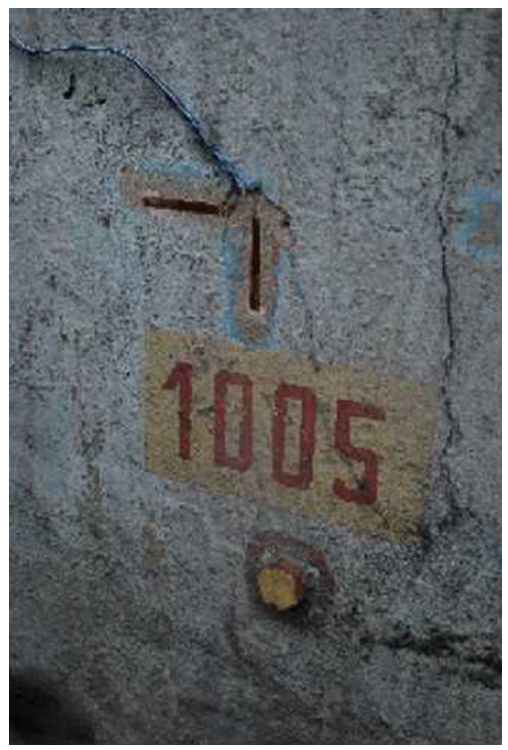


Fig. 6 Measuring point (accelerometer) located at the level of the exhaust wheels
Fig. 7 Sketch layout of the accelerometers at the level of the driving wheels
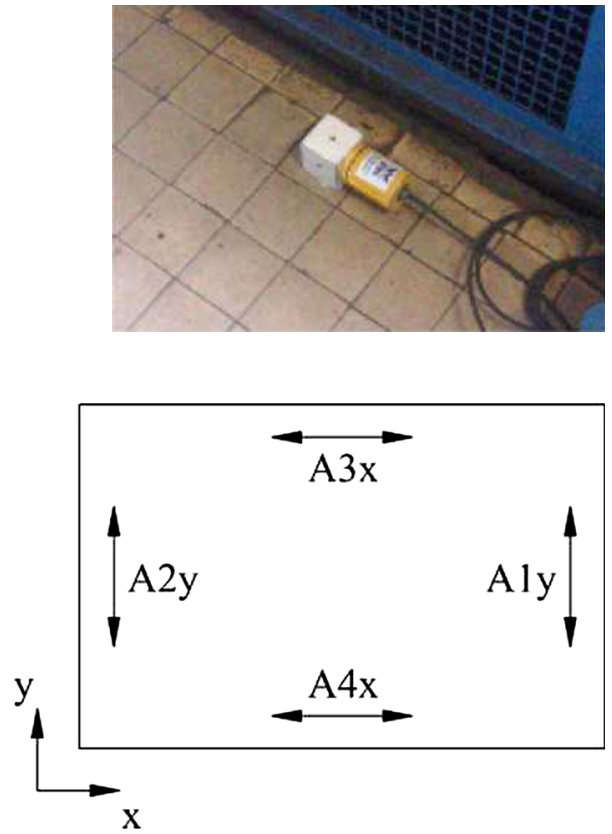

Table 4 Summary of the maximum values of the recorded vibrations, $\left(\mathrm{cm} / \mathrm{s}^{2}\right)$

\begin{tabular}{lllll}
\hline Excitation & \multicolumn{4}{l}{ Gauge } \\
\cline { 2 - 5 } & $\mathrm{A} 1 \mathrm{y}$ & $\mathrm{A} 2 \mathrm{y}$ & $\mathrm{A} 3 \mathrm{x}$ & $\mathrm{A} 4 \mathrm{x}$ \\
\hline Wind gust & $0.38-0.57$ & $0.50-0.83$ & $0.21-0.36$ & $0.24-0.34$ \\
Machine work & $0.63-1.23$ & $0.64-1.08$ & $0.69-2.10$ & $0.56-2.37$ \\
Men swaying & $0.29-0.60$ & $0.31-0.54$ & $0.20-0.34$ & $0.17-0.33$ \\
\hline
\end{tabular}

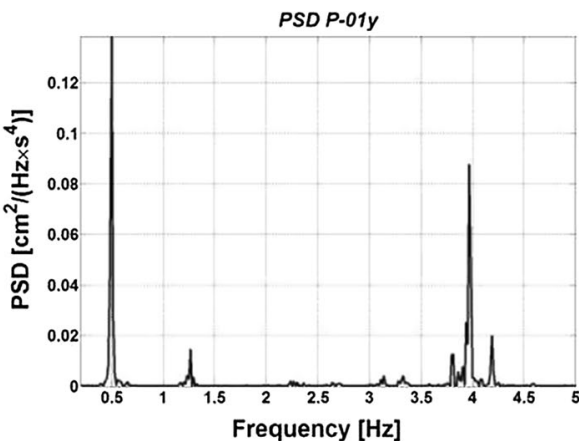

Fig. 8 Result of the FFT analysis and PSD functions of the horizontal component ' $y$ ' of tower vibration due to the wind gusts

Toolbox 2000). Figures 8, 9 and 10 show exemplary FFT and PSD plots determined for the horizontal component (' $y$ ') measured at the level of the exhaust wheels (gauge A1y). Dynamic excitation was caused by the wind gust (Fig. 8), the slide of the two skips 

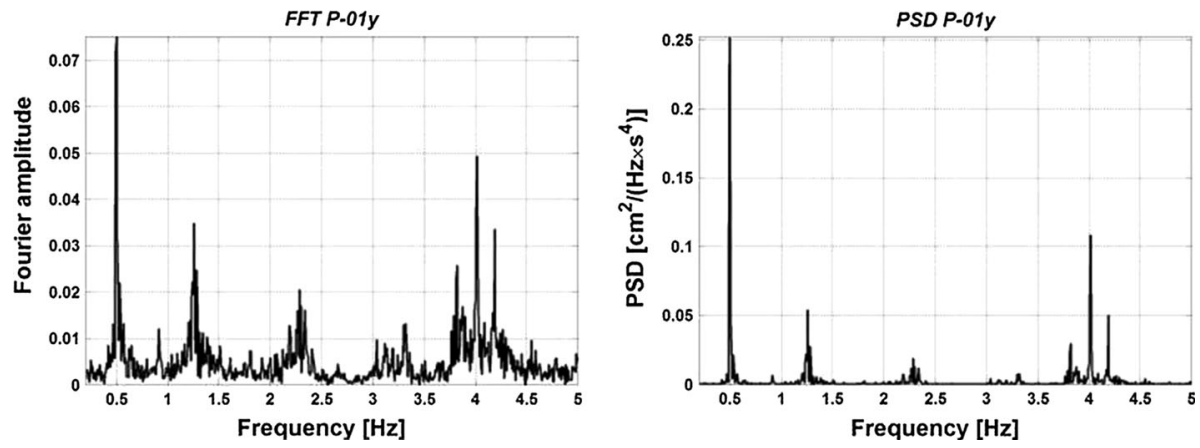

Fig. 9 Result of the FFT analysis and PSD functions of the horizontal component ' $y$ ' of tower vibration due to the slide of the two skips
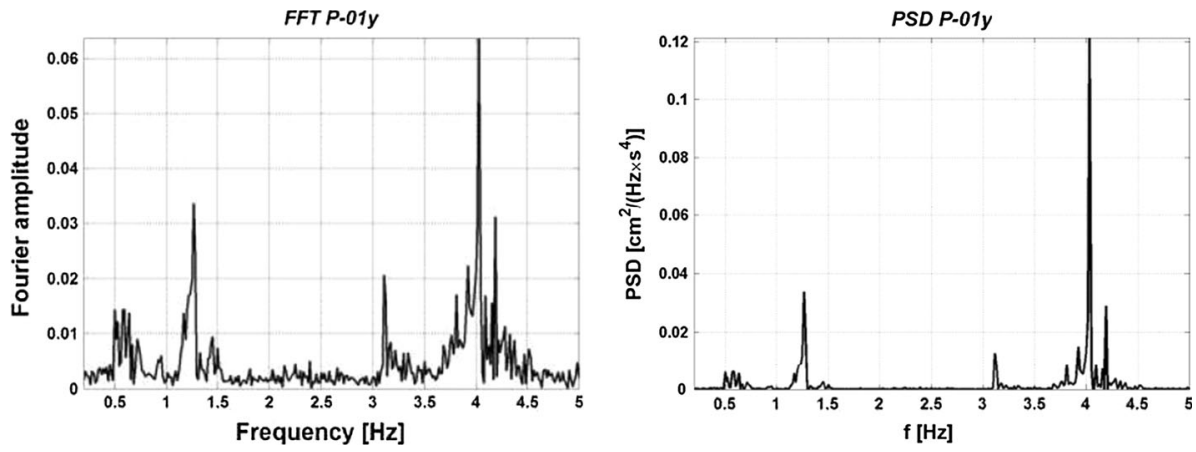

Fig. 10 Result of the FFT analysis and PSD function of the horizontal component ' $y$ ' of tower vibrationexcitation by the coordinated men swaying

(Fig. 9), and a coordinated swaying of the group of men in opposite directions along the shorter side of the skip tower (Fig. 10).

Preliminary comparison of the calculated and measured values of the first three frequencies was given by Tatara et al. 2013. The analyses of the measured records made it possible to determine the natural frequencies of the analysed structure, which are shown in Table 5. The first two natural frequencies are low and less than $1(\mathrm{~Hz})$. They refer to flexural mode shape in the ' $y$ ' and ' $x$ ' directions, respectively.

The calculated results of the natural frequencies of the tower were analysed and compared with those obtained on the basis of measurements in situ. Table 6 shows the comparison of natural frequencies of the analysed structure.

Table 5 Natural frequencies of the tower based on dynamic measurements $(\mathrm{Hz})$

\begin{tabular}{ll}
\hline Value of frequency & Mode shape \\
\hline $0.50-0.51$ & Flexural in ' $y$ ' direction \\
$0.65-0.67$ & Flexural in ' $x$ ' direction \\
$1.23-1.27$ & Torsional \\
3.11 & Flexural in ' $y$ ' direction \\
4.18 & Flexural in ' $x$ ' direction \\
\hline
\end{tabular}


Table 6 Comparison of the measurement results with those obtained using the theoretical model of the structure

\begin{tabular}{lll}
\hline $\begin{array}{l}\text { Value of frequency from } \\
\text { measurements }(\mathrm{Hz})\end{array}$ & $\begin{array}{l}\text { Calculated value of } \\
\text { frequency }(\mathrm{Hz})\end{array}$ & $\begin{array}{l}\text { Difference }(\%) \text { between the calculated } \\
\text { and measured values of the frequencies }\end{array}$ \\
\hline $0.50-0.51$ & 0.5 & $0-2$ \\
$0.65-0.67$ & 0.72 & $6.9-9.7$ \\
$1.23-1.27$ & 1.53 & $19.6-19.9$ \\
3.11 & 3.06 & 1.6 \\
4.18 & 4.23 & 3.2 \\
\hline
\end{tabular}

The results obtained from the numerical analyses using the 3D FEM model of the skip tower are similar to the results obtained from the dynamic investigation in situ. The first fundamental frequency of vibration is accurately imitated in the model. This corresponds to the natural frequency of vibration in the direction of the lower stiffness structure (direction ' $y$ '). This frequency is important for the determination of the wind load (PN-EN 1991-1-4 Eurocode 1 1991; Riera and Davenport 1998). Very strong agreement was also obtained for the second natural frequency, for which the difference between the measured and calculated values does not exceed $10 \%$. For the third natural frequency, a torsional mode shape was confirmed while the difference in the quantitative convergence is about $20 \%$.

\subsection{Assumed kinematic loads and dynamic analysis}

The kinematic excitations were adopted in the form of the records of the horizontal components of ground acceleration vibrations caused by earthquake and mining tremor. The earthquake records were registered in the district of Sitka, Alaska (USA) (Fig. 11).
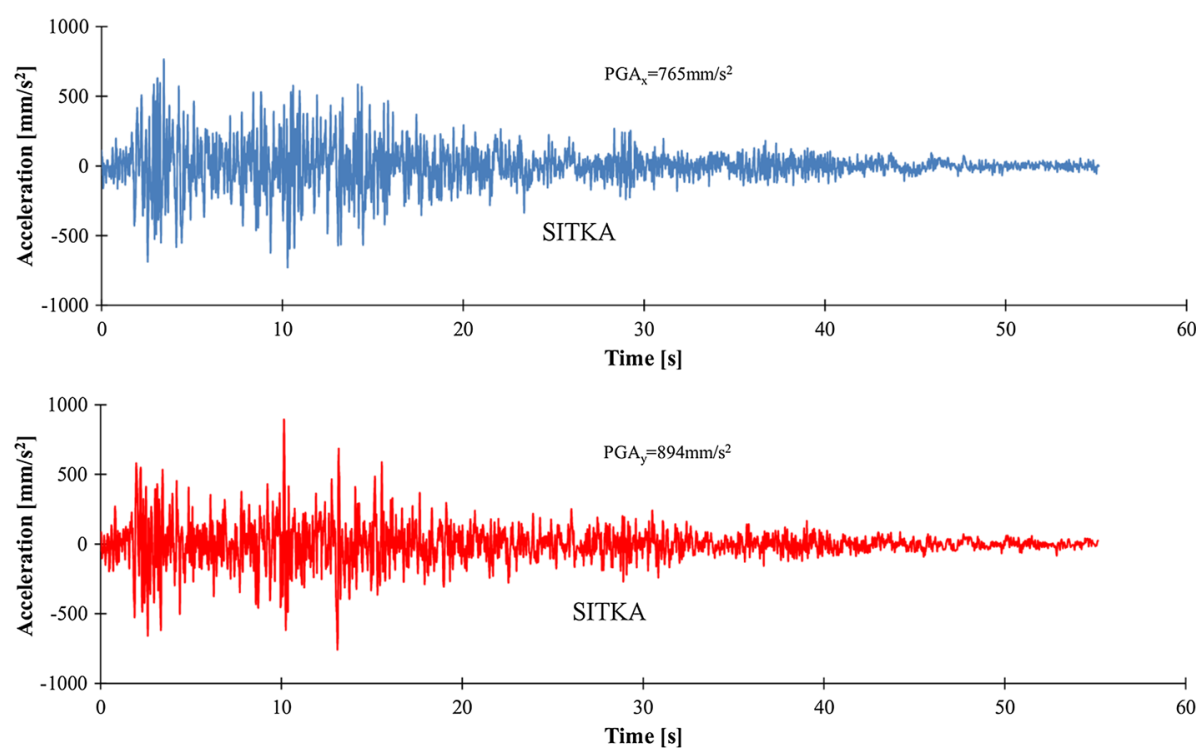

Fig. 11 The horizontal components of earthquake records used in the analysis 
Unlike earthquakes, which result simply from tectonic plates pushing against one another, mining tremors are a regional phenomenon resulting from human activities. In Poland, their occurrence is related to the mining of mineral resources such as coal, lignite and copper ore. When one excavates a part of the deposit and removes some rocks bordering the selected space, zones of increased pressure are formed in the rock mass surrounding the excavation zone, and the stress state seems to deviate from the normal state. As a result, elastic energy accumulates in the subsurface - this does not last for a long time and leads to a spontaneous process of the rocks regaining their balance. Elastic energy accumulated in rocks, after it exceeds the rock strength, is rapidly discharged in a manner similar to that of an explosion. The sudden relaxation of the rock mass at hypocentral depths of mining tremors results in propagation of seismic waves. Mining tremors are not only direct and instant dynamic vibrations but can also be characterised by the accumulated dynamic response of a rock mass disturbed by mining activities (Cai et al. 2005). In the surface layer, surface waves are formed. Many authors have studied the phenomenon of propagation and amplification of seismic waves in soils (Driad-Lebeau et al. 2009; Semblat et al. 2000, 2005). Surface waves have the greatest impact on surface structures, particularly their horizontal components. One of the most exploited areas in Poland is the LegnicaGłogowski Copper District (LGCR). Every year, several strong shocks of energy-not less than $10^{7}(\mathrm{~J})$ - are recorded. One of the most intense shocks registered in LGCR since the time continuous recording was introduced took place on 21th May 2006. Its energy $\left(E_{n}\right)$ was equal to $1.9 \mathrm{E} 9(\mathrm{~J})$. These mining records are at their most intensive at this area. Horizontal components of acceleration vibrations for that shock registered on one of numerous seismic stations located in the LGCR were used as the kinematic load for the analyzed skip tower (Fig. 12). The maximum value of $\left(\mathrm{PGA}_{\mathrm{y}}\right)$ for assumed mining excitation is comparable with $\left(\mathrm{PGA}_{\mathrm{y}}\right)$ value for SITKA earthquake, while the maximum value of $\left(\mathrm{PGA}_{\mathrm{x}}\right)$ for mining tremors is twice as great as in the case of earthquake. Table 7 presents a comparison of basic parameters characterising surface horizontal components of
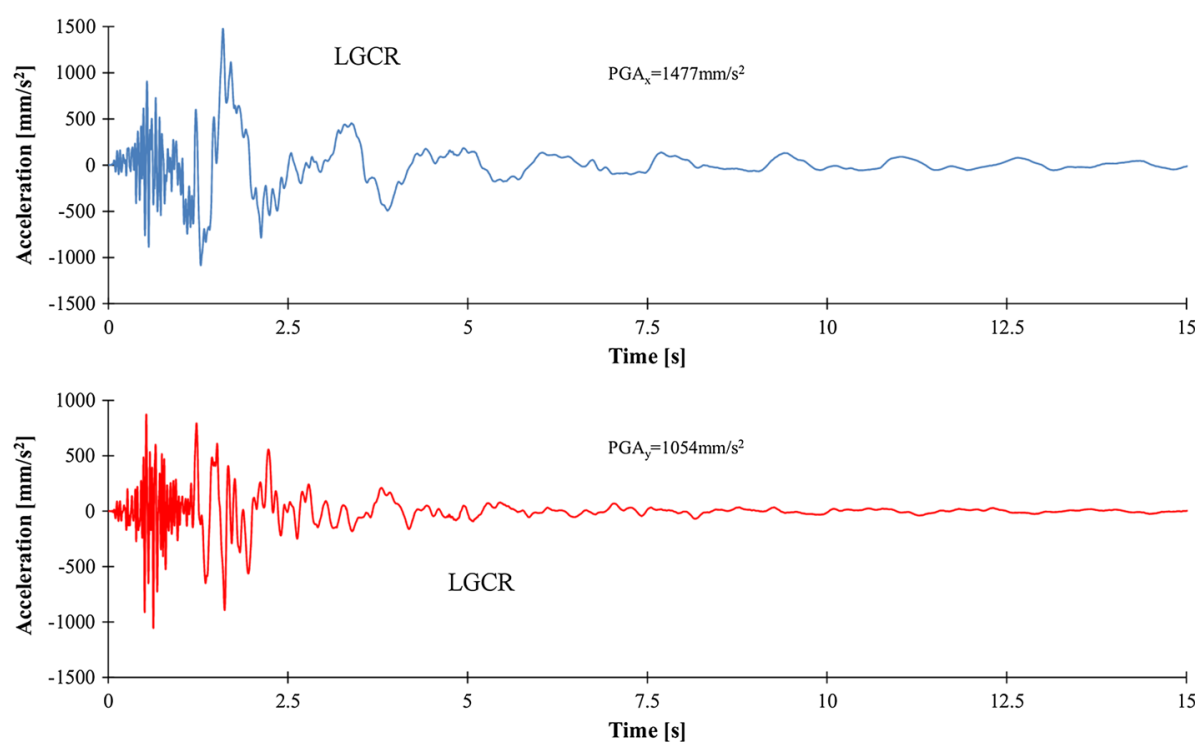

Fig. 12 The horizontal components of mining vibration records used in the analysis 
Table 7 Characteristics of the analysed components of vibrations

\begin{tabular}{lccclllrr}
\hline No. & $\begin{array}{l}\mathrm{PGA}_{\mathrm{x}} \\
\left(\mathrm{mm} / \mathrm{s}^{2}\right)\end{array}$ & $\begin{array}{l}\mathrm{PGA}_{\mathrm{y}} \\
\left(\mathrm{mm} / \mathrm{s}^{2}\right)\end{array}$ & $\begin{array}{l}\mathrm{PGV}_{\mathrm{x}} \\
(\mathrm{mm} / \mathrm{s})\end{array}$ & $\begin{array}{l}\mathrm{PGV}_{\mathrm{y}} \\
(\mathrm{mm} / \mathrm{s})\end{array}$ & $\begin{array}{l}\mathrm{PGA}_{\mathrm{x}} / \mathrm{PGV}_{\mathrm{x}} \\
(-)\end{array}$ & $\begin{array}{l}\mathrm{PGA}_{\mathrm{y}} / \mathrm{PGV}_{\mathrm{y}} \\
(-)\end{array}$ & $\begin{array}{r}\mathrm{t}_{\mathrm{ha}} \\
(\mathrm{s})\end{array}$ & $\begin{array}{r}\mathrm{t}_{\mathrm{hv}} \\
(\mathrm{s})\end{array}$ \\
\hline 1 & 765 & 894 & 74.2 & 67.0 & 10.3 & 13.3 & 27.1 & 28.9 \\
2 & 1477 & 1054 & 180.2 & 48.2 & 8.2 & 21.9 & 5.1 & 3.4 \\
\hline
\end{tabular}

the analysed vibrations. The duration of the intensive phase of acceleration $\left(t_{\text {ha }}\right)$ and velocity $\left(t_{h v}\right)$ for each horizontal component of vibration was calculated from the standard chart of Arias intensity. The summary of the parameters characterising the analysed components of vibrations shows some differences between earthquakes and mining tremors. The most significant difference between earthquakes and mining tremors is the duration of the intensive phase of the vibration, which in the case of the analysed earthquake lasted for $30 \mathrm{~s}$. In the case of mining tremors, it slightly exceeded $5 \mathrm{~s}$. The frequency characteristics of the assumed seismic occurrences are also different. Figure 13 shows a Fourier spectrum of the most intensive components of the examined vibrations. The values of (PGA/PGV) ratio are similar for both events - this means that the strongest mining tremors correspond to weak shallow earthquakes. Higher values of maximal acceleration are recorded for mining tremors than for an earthquake. It should be emphasised that the mining tremor analysed in the study was one of the most intense events in this area; however, maximal values of acceleration do not normally exceed $0.15 \mathrm{~g}$ (g-acceleration of gravity).

Backward dynamic analysis of the assumed linear model of the original tower was performed in order to determine the behaviour of the tower due to the kinematic excitations discussed above. Results of the calculations indicate, among other things, the possible locations of damage (concentrations of stresses). Dynamic calculations were performed in the time domain using the modal superposition method (EN 1998-1 Eurocode 8 1998).
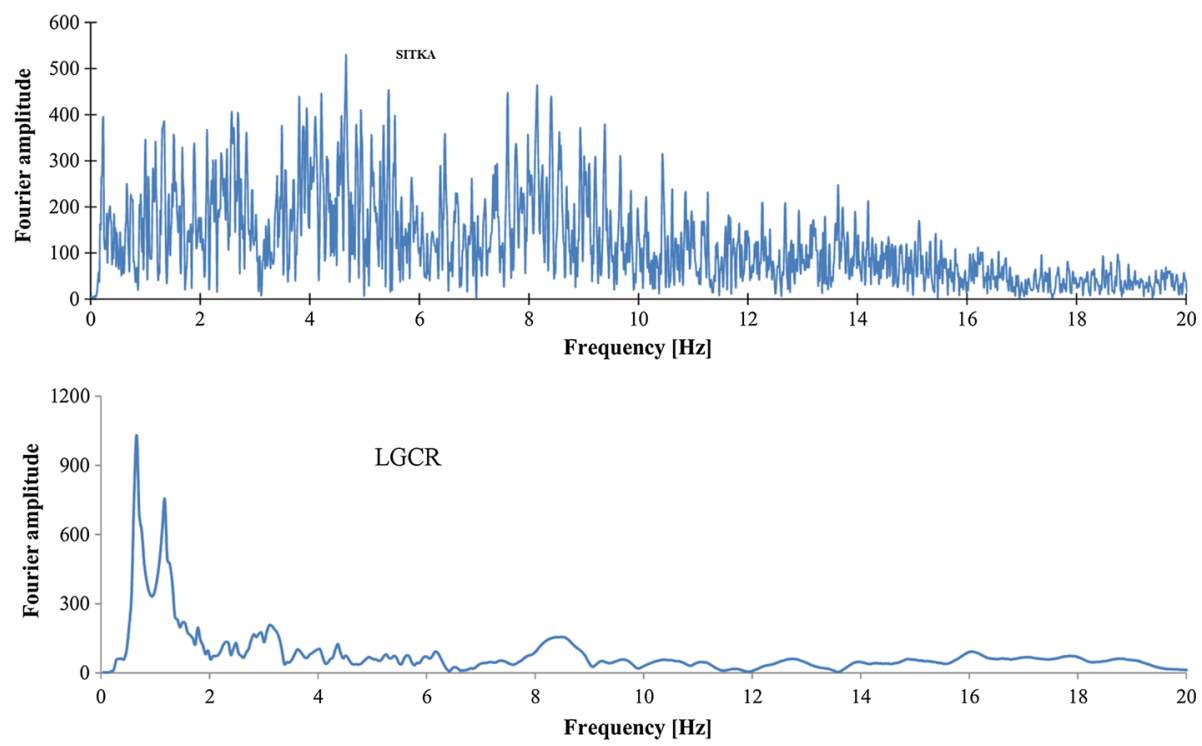

Fig. 13 Fourier spectrum for the most intensive components of the vibrations 
Modal analysis allows the passage of conjugated equations of motion to the separated equations, by using the relevant product transformation (Yang et al. 1990) - this simplifies the calculations. In each case of calculations, a dominant horizontal component of vibration in the direction of the lower rigidity of the model was assumed. The first one hundred mode shapes of the skip tower were taken into account, even including those frequencies corresponding to the local mode shapes of individual load-bearing elements. The value of critical damping ratio $\xi=2.5 \%$ was adopted according to investigations, the results of which were presented by Ciesielski et al. (1995).

\subsection{Results of dynamic analysis}

Generally, in the dynamic analysis combination of the dead load, the dynamic load (kinematic excitation), the wind load and soil pressure on the embedded walls is considered. Table 8 presents a comparison of selected resultant results for the two adopted kinematic excitations. The calculation only includes kinematic excitation, it does not include any other loads (e.g. technological). Calculated stresses and displacements obtained in this way allow us to analyse the dynamic response of the model due to kinematic loads originating from the earthquake and the mining shock.

Comparing the results shown in Table 8, it can be stated that the level of displacement in the case of a mining shock is larger than for the analysed earthquake. In particular, it refers to the component ' $y$ ', which dominates distinctly in the case of a mining tremor. Due to the fact that most of the energy of a mining tremor is transferred at a low-frequency band closer to the natural frequency of the tower model, this results in higher values of displacement and stress (both tensile and compressive). Figure 14 shows the character of deformation at the maximum deflection of the tower due to SITKA earthquake. Transparently, in Fig. 14 the undeformed model is shown. It may be noted that the model response corresponds to the first bending mode shape (Fig. 4). A similar phenomenon is observed in the case of mining tremor excitation. This mode is accompanied by the largest vertical stress $\sigma_{z z}$. The stresses concentrate at the point of stiffness change between the underground RC rigid foundation box and section with less rigid RC pylons. Figure 15 shows the vertical stress distribution and the location of the maximum and minimum values listed in Table 8. Such a deformation as that which is shown in Fig. 14 is a threat to the stability of a high structure due to the possibility of overturning it. Figure 16 shows the distribution of displacement vector under the foundation slab resulting from the Sitka earthquake and taking the weight of the tower into account. This distribution confirms that there are no tensile stresses under the slab-this means that the value of the moment

Table 8 Chosen resultant results for analysed kinematic loads

\begin{tabular}{llc}
\hline Calculated results & SITKA & LGCR \\
\hline Displacement ' $x$ ' at level $+80.01(\mathrm{~cm})$ & 1.43 & 1.63 \\
Displacement ' $y$ ' at level $+80.01(\mathrm{~cm})$ & 3.06 & 8.42 \\
Magnitude displacement at level $+80.01(\mathrm{~cm})$ & 3.22 & 8.70 \\
Displacement ' $x$ ' at level $+95.77(\mathrm{~cm})$ & 1.64 & 1.82 \\
Displacement ' $y$ ' at level $+95.77(\mathrm{~cm})$ & 3.59 & 9.74 \\
Magnitude displacement at level $+95.77(\mathrm{~cm})$ & 3.77 & 9.95 \\
Stress $\boldsymbol{\sigma}_{z z}$ (compression) in pillar $(\mathrm{MPa})$ & 6.57 & 16.35 \\
Stress $\boldsymbol{\sigma}_{z z}$ (tension) in pillar $(\mathrm{MPa})$ & 5.97 & 15.84 \\
\hline
\end{tabular}


Fig. 14 Deformation mode corresponding to the maximal inclination of the tower due to an earthquake

$\begin{gathered}\text { Displacement } \\ \text { Magnitude } \\ \mathrm{m}\end{gathered}$
0.04471
0.03997
0.03523
0.03049
0.02575
0.02101
0.01627
0.01153
0.006791
0.002051

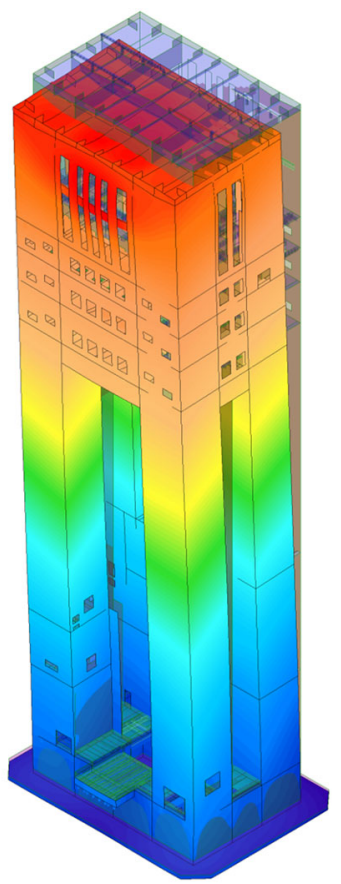

related to the weight of the structure is higher than the value of the overturning moment caused by kinematic excitation.

For a more detailed presentation of the dynamic investigation results, two walls were selected-one transverse in axis 4 and the other longitudinal in axis D (Fig. 17). From the time domain, the moment at which maximum deflection in horizontal directions ' $x$ ' and ' $y$ ' occurs was chosen. Figures 18, 19, 20 and 21 show selected results for the walls located in the 4 and $\mathrm{D}$ axes.

The cantilever nature of the structure work corresponding to the first mode shape can be seen in the vertical stress $\sigma_{\mathrm{zz}}$ distributions shown in Figs. 18 and 19. A dead load causes domination of the compressive stresses in the transverse and longitudinal walls. Horizontal kinematic excitation causes stresses of the bending type. Localisation of the maximum stress values takes place in the area of the restraint pylon tower at a much stiffer underground part of the tower. Stresses $\sigma_{z z}$ in both selected walls are significantly greater than in the case of an earthquake (SITKA). The range of the increased stresses is also greater in the case of the mining tremor whereas stress distributions are qualitatively similar. This confirmed the fact that in a structure with such dynamic characteristics and kinematic excitations, the first mode shapes dominates the response. Lack of access to the structure documentation, which generally should give information about the amount of reinforcement in the RC elements, enables verification of the load capacity of the critical sections.

A further stage of the analysis was to define the zones in which the maximum principal tensile stresses exceeded the adopted tensile strength of concrete (contractually assumed concrete tensile strength is equal to $2.0(\mathrm{MPa})$ ). Also in this case, the presentation of the results was limited to two selected walls in axes 4 and D. Figures 20 and 21 present areas in which values of the principal tensile stresses exceed the adopted allowable value (red). 
Fig. 15 Vertical stress

distribution corresponding to the maximal inclination of the tower due to an earthquake
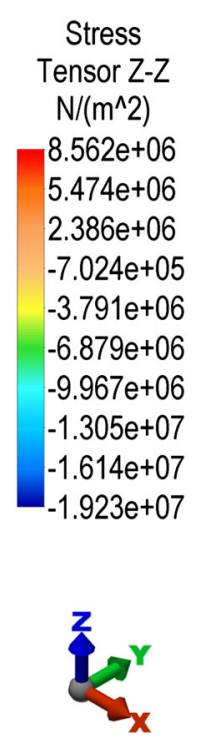

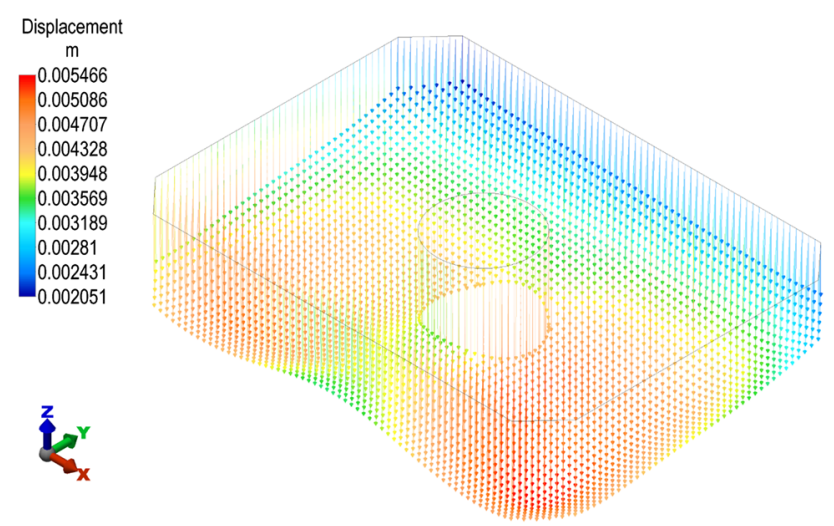

Fig. 16 Displacement distribution of the foundation slab due to an earthquake assuming dead load

In both cases of kinematic loads, the concentration of principal tensile stresses can be seen in the lower parts of the analysed model in the region of the underground grid built from the basement slab, the ceiling slab and the walls. These concentrations are mainly caused by the pressure of the soil on the surface under the exterior walls. This type of load was taken into account during the development stage. Increases in the stress values resulting from kinematic excitation for both the mining tremor (LGCR) and the earthquake (SITKA) does not exceed 10\%. There are very important areas of increased stresses located in the upper section, where the change of stiffness occurs due to transition from a system of four box pylons to one solid limited only by outer walls. Similarly, as in the case of vertical stresses, the area in which the principal tensile stresses exceed $2.0(\mathrm{MPa})$ is much greater 

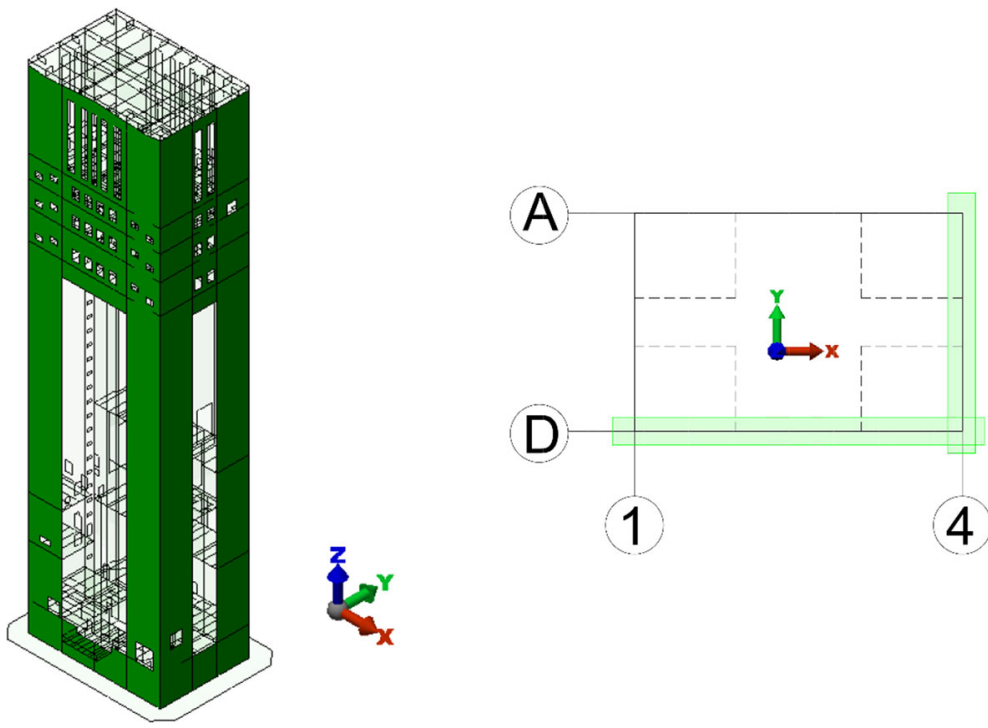

Fig. 17 Walls selected for detailed results presentation
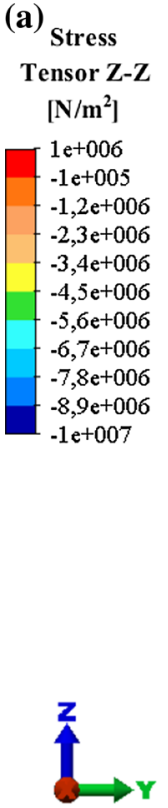

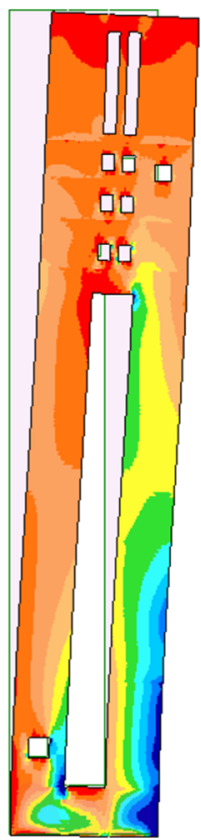

(b)
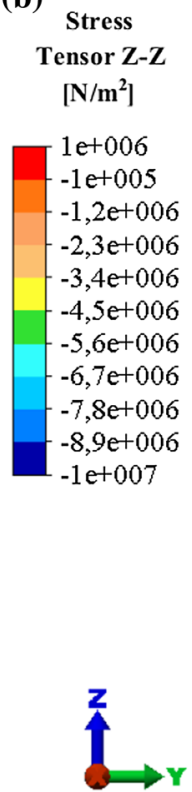

Fig. 18 Stress $\sigma_{\mathrm{zz}}$ distribution for the wall in axis 4 due to mining tremor LGCR (a) and earthquake SITKA (b) 

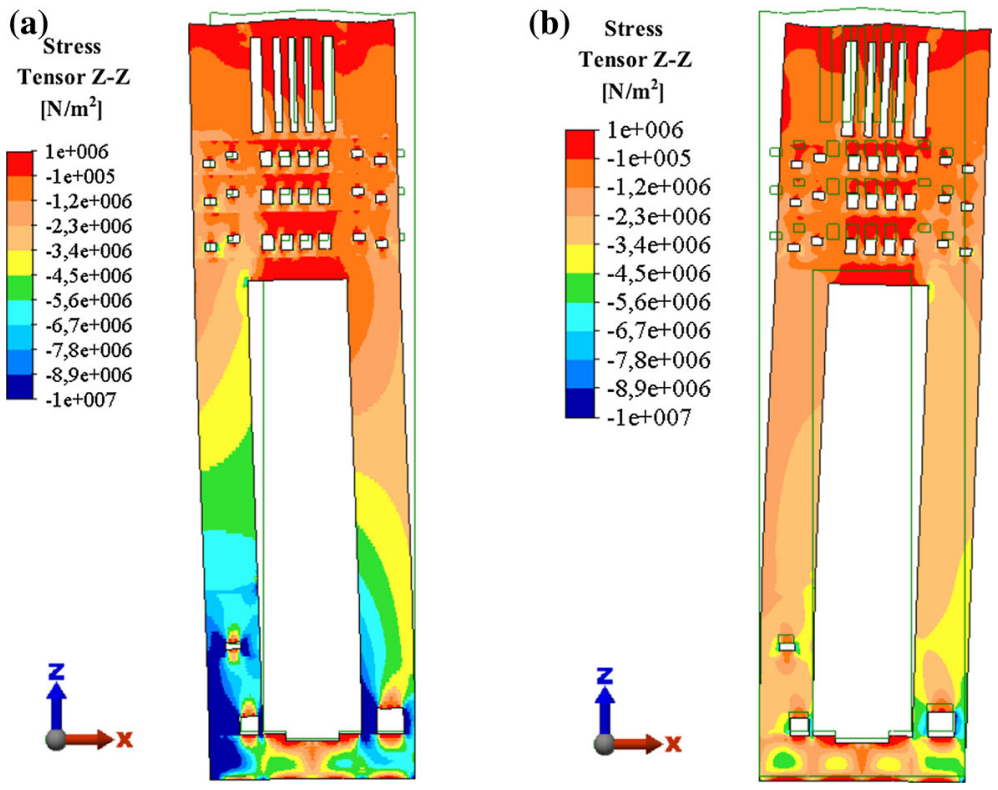

Fig. 19 Stress $\sigma_{z z}$ distribution for the wall in axis D due to mining tremor LGCR (a) and earthquake SITKA (b)
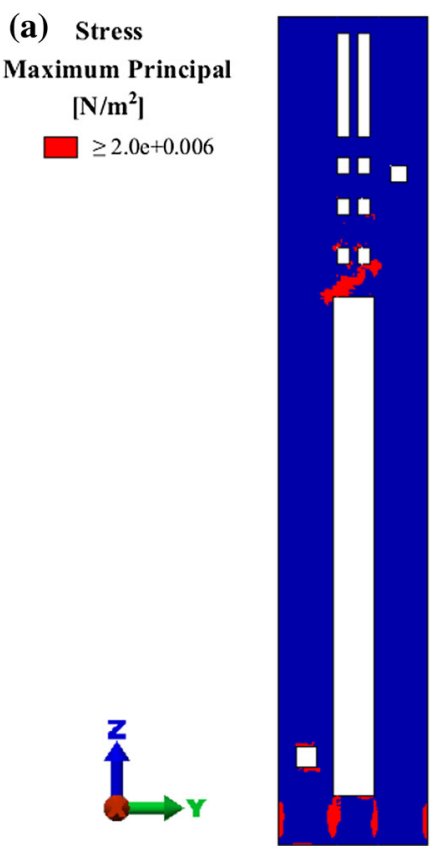
(b) Stress Maximum Principal $\left[\mathbf{N} / \mathbf{m}^{2}\right]$
$\geq 2.0 \mathrm{e}+0.006$

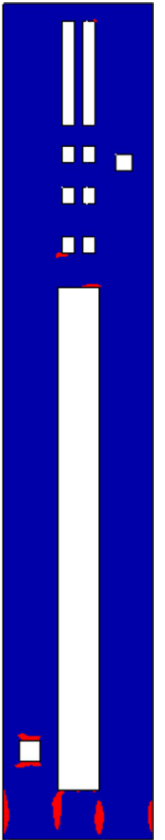

Fig. 20 Areas where the principal tensile stresses exceeded the contractual value of 2.0 (MPa) for the wall in axis 4 caused by mining tremor LGCR (a) and earthquake SITKA (b) 

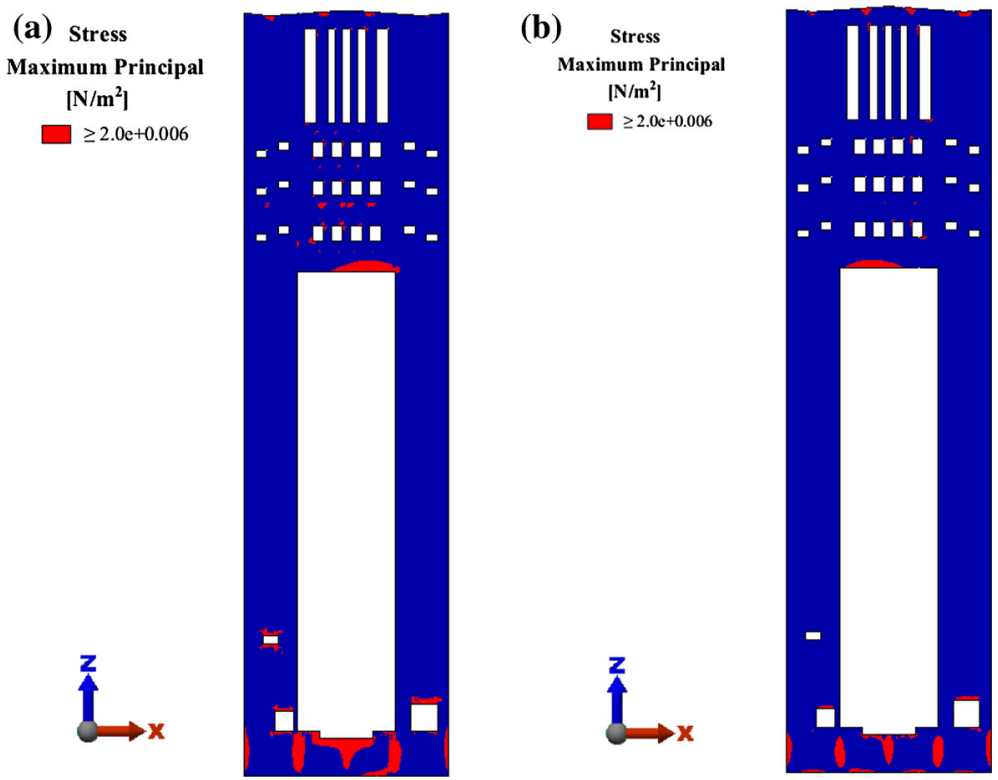

Fig. 21 Areas where the principal tensile stresses exceeded the contractual value of $2.0(\mathrm{MPa})$ for the wall in axis D caused by mining tremor LGCR (a) and earthquake SITKA (b)

for kinematic loading resulting from mining tremor (LGCR) than the eathquake (SITKA). Also in this case, distributions of the stresses are qualitatively similar. The current technical conditions of the tower confirm the results of calculations due to the presence of areas with larger limit values of tensile stress.

The study analysed the behaviour of the linear model of the tower subjected to the actual strongest mining shock recorded in the LGCR and for comparative purposes SITKA earthquake. The calculated results indicate that the tensile stress overcome material strengths at a certain step of calculations. Therefore the authors consider that the behaviour of the structure can be strongly nonlinear and ground acceleration can cause a different reaction of the structure.

\section{Comparison of the model response due to kinematic and code wind loads}

The computed values of dynamic displacements, stresses and distribution of the foundation slab displacements were compared with the results obtained for the code wind loads. The wind load was determined on the basis of standard (PN-EN 1991-1-4 Eurocode 1 1991) for the location of structures in Poland. This load was the basic load considered in the design procedure, apart from the technological loads related to the use of this structure. Values of coefficients of aerodynamic resistance were defined on the basis of the results presented by Haniu and Sakamoto (1987), and code (PN-80/B-03040 1980), mainly because of the unusual shape of the tower that consists of four pillars located at a close distance from one another. Table 9 presents the selected results for wind loads-this can be compared with 
Table 9 Selected calculated results in the case of wind load

\begin{tabular}{ll}
\hline Selected results & Wind load \\
\hline Displacement ' $x$ ' at level $+80.01(\mathrm{~cm})$ & 0.48 \\
Displacement ' $y$ ' at level $+80.01(\mathrm{~cm})$ & 2.12 \\
Magnitude displacement at level $+80.01(\mathrm{~cm})$ & 2.17 \\
Displacement ' $x$ ' at level $+95.77(\mathrm{~cm})$ & 0.55 \\
Displacement ' $y$ ' at level $+95.77(\mathrm{~cm})$ & 2.45 \\
Magnitude displacement at level $+95.77(\mathrm{~cm})$ & 2.51 \\
Stress $\boldsymbol{\sigma}_{z z}$ (compression) in pillar $(\mathrm{MPa})$ & 3.53 \\
Stress $\boldsymbol{\sigma}_{z z}$ (tension) in pillar $(\mathrm{MPa})$ & 5.24 \\
\hline
\end{tabular}

the values obtained for the analysed kinematic excitations. Greater values of calculated displacements and stresses are obtained for selected kinematic excitations than for wind loads. In particular, the displacements and stresses induced by mining tremors have the greatest value. In the worst case, the level of maximum displacement and stress is almost four times higher than for wind loads. In the case of wind loads, there is no danger of the tower losing its stability that protects it from falling over.

\section{Conclusion}

The study presents the influence of one of the most intensive mining tremors and earthquakes on the skip tower. This structure is a strategic device for the operation of a coal mine and its exclusion from the use in the event of an accident or damage would constitute a great loss for the mine. Dynamic analyses were performed using 3D model FEM and the modal superposition method. An analysis was also conducted for wind loads. All results were compared and commented on and were the basis for the formulation of conclusions.

If the tower was located in a seismically active area, the appropriate standards would have to be used in the design procedure. Therefore, in the design process, additional stresses (cross-sectional forces) resulting from an earthquake would need to be considered. However, in Poland, at the time when the skip tower was designed, no standards or instructions for the design of structures in mining shock areas existed. The primary loads for such a structure were wind and technological loads.

The calculation results indicate that the kinematic load of the base of the structure due to mining tremors can be a basic design load, as it is for earthquakes in seismically active areas. In this particular case, the mining-related load caused greater displacements than earthquakes or wind. Similarly, the stress in the main structural components was higher. Analysis of the technical state of the existing tower confirmed the presence of surface defects in the areas indicated in the calculation.

In Poland, there are a number of industrial buildings that belong to the mines that were not designed for seismic impact caused by mining tremors. The approach presented here, connected with creating a representative FEM model and performing calculations using the recorded components of vibrations, is a good method for predicting the negative effects of such loads.

Quantitative analysis of mining tremors in the LGCR area indicates, that analysed mining shock in the paper is one of the most intense phenomenon recorded so far in this area. Although mining tremors caused by underground exploitation are random 
phenomena, there is a probability of appearance of mining tremors with a greater intensity than analyzed at the study. In such cases, nonlinear model of stiffness degradation should be considered.

Open Access This article is distributed under the terms of the Creative Commons Attribution 4.0 International License (http://creativecommons.org/licenses/by/4.0/), which permits unrestricted use, distribution, and reproduction in any medium, provided you give appropriate credit to the original author(s) and the source, provide a link to the Creative Commons license, and indicate if changes were made.

\section{References}

Cai MF, Ji HG, Wang JA (2005) Study of the time-space-strength relation for mining seismicity at Laohutai coal mine and its prediction. Int J Rock Mech Min Sci 42(1):145-151

Ciesielski R (1973) Evaluation of harmfulness of dynamic influences in building. Arkady, Warszawa, p 252 (in Polish)

Ciesielski R, Kuźniar K, Maciąg E, Tatara T (1995) Damping of vibration in precast buildings with bearing concrete walls. Arch Civil Eng 41(3):329-341

Driad-Lebeau L, Lokmane N, Semblat JF, Bonnet G (2009) Local amplification of deep mining induced vibrations part 1: experimental evidence for site effects in a coal basin. Soil Dyn Earthq Eng 29(1):39-50

EN 1998-1 Eurocode 8 (1998) Design of structures for earthquake resistance—part 1: general rules, seismic actions and rules for buildings (European standard EN 1998, December 2004)

Gad EF, Wilson JL, Moore AJ, Richards AB (2005) Effects of mine blasting on residential structures. J Perform Constr Facil 19:222-228

Haniu H, Sakamoto H (1987) Fluctuating forces acting on two rectangular prisms placed vertically in a turbulent boundary layer. J Wind Eng Ind Aerodyn 26(1):85-103

Kuźniar K, Tatara T (2015) Dynamic investigations of various civil engineering structures due to ambient and mining tremors. In: Feltrin $\mathrm{G}$ (ed) Proceedings of the 6th international conference on experimental vibration analysis for civil engineering structures EVACES'15, Duebendorf (Zurich), Switzerland, 19-21 Oct, pp 153-156. doi: 10.1051/matecconf/20152404008

Maciąg E, Kuźniar K, Tatara T (2016) Response spectra of the ground motion and building foundation vibrations excited by rockbursts in the LGC region. Earthq Spectra 32(3):1769-1791. doi:10.1193/ 020515EQS022M

Manfredi G, Prota A, Verderame GM et al (2014) Bull Earthquake Eng 12:2275. doi:10.1007/s10518-0139512-X

PN-80/B-03040 (1980) Machine foundations and supporting structures, Calculation and design (in Polish)

PN-85/-02170 (1985) Evaluation of the harmfulness of building vibrations due to ground motion (in Polish)

PN-EN 1991-1-4 (191) Eurocode 1-influence on constructions, part 1-4: general influence-wind influence

Pytel W (2003) Rock mass-mine workings interaction model for polish copper mine conditions. Int J Rock Mech Min Sci 40:497-526

Riera JD, Davenport AG (1998) Wind effects on buildings and structures: In: Proceedings of the jubilee conference on wind effects on buildings and structures, Balkema, Rotterdam

Semblat JF, Duval AM, Dangla P (2000) Numerical analysis of seismic wave amplification in nice (France) and comparisons with experiments. Soil Dyn Earthq Eng 19(5):347-362

Semblat JF, Kham M, Parara E, Bard PY, Pitilakis K, Makra K, Raptakis D (2005) Site effects: basin geometry versus soil layering. Soil Dyn Earthq Eng 25(7-10):529-538

Singh PK, Roy MP (2010) Damage to surface structures due to blast vibration. Int J Rock Mech Min Sci 47:949-961

Tatara T (2012) Dynamic resistance of buildings in mining tremors conditions. Publishing House Cracow University of Technology, Cracow, p 258 (in Polish)

Tatara T, Pachla F (2010a) Chosen criteria for estimation of dynamic resistance of masonry buildings subjected to mining tremors. Tech Trans Civil Eng (3-B)/2010 issue 11:161-172 (in Polish)

Tatara T, Pachla F (2010b) Action of mining tremors in LGCR and BBCR on masonry buildings and selected criteria for the evaluation of their dynamic resistance. Res Rep Cent Min Inst Min Environ Quart Spec Issue 4(4):139-158 (in Polish) 
Tatara T, Pachla F (2011) Influence of mining tremors on industrial structures. In: Proceedings of the 9th international conference on new trends in statics and dynamics of buildings, Bratislava, Slovakia, 20-21 Oct, pp 153-156

Tatara T, Pachla F (2012) Influence of earthquakes and mining related surface vibrations on RC skip tower. In: Proceedings of the 15th world conference on earthquake engineering WCEE Lisbon, Portugal, 24-28 Sep. WCEE2012_4188.pdf

Tatara T, Pachla F, Kuboń P (2013) Dynamic and stability analysis of the tall surface RC mining structure. In: Kienzler R and Boettcher S (eds) Proceedings of the 8th german-greek-polish symposium recent advances in mechanics, Goslar, Germany, 09-13 September. Book of abstracts University of Bremen. Department of Production Engineering, pp 81-82

The Math Works. Inc MATLAB Signal Processing Toolbox. User's Guide, 2000

Yang JN, Sarkani S, Long FX (1990) A response spectrum approach for seismic analysis of nonclassically damped structures. Eng Struct 12:173-184

Zembaty Z (2004) Rockburst induced ground motion—a comparative study. Soil Dyn Earthq Eng 24:11-23

Zembaty Z (2011) How to model rockburst seismic loads for civil engineering purposes? Bull Earthq Eng 9:1403-1416. doi:10.1007/s10518-011-9269-Z

Zembaty Z, Kokot S, Bozzoni F, Scandella L, Lai CG, Kuś J, Bobra P (2015) A system of mitigate deep mine tremors effects in the design of civil infrastructure. Int J Rock Mech Min Sci 74:81-90. doi:10. 1016/j.ijrmms.2015.01.004 